\title{
A face territorial do desenvolvimento
}

El faz territorial del desarrollo

The territorial face of the development

José Eli da Veiga

Universidade de São Paulo

Contato: veiga@msh-paris.fr

Resumo: Observa-se, de maneira geral, o emprego cada vez mais freqüente da expressão "desenvolvimento territorial" ou, por vezes, "desenvolvimento espacial". Tal tendência pode indicar uma revalorização da dimensão espacial da economia, mas pode, igualmente, refletir o hábito corrente de se acrescentar adjetivos ao substantivo "desenvolvimento". A investigação aqui exposta permite avançar proposições que decorrem dos debates sobre as tendências da diferenciação espacial cidade/campo, sobre a heterogeneidade espacial do dinamismo econômico e sobre as iniciativas locais que podem ser cruciais para o desenvolvimento. Procura-se, dessa forma, estabelecer as principais relações desses debates com a evolução do "planejamento regional".

Palavras-chave: Planejamento regional; Meio inovador; Desenvolvimento territorial.

Abstract: It is observed, in general, the frequent use of the expression "territorial development" or, some times, "spacial development". Such trend can indicate a revalorization of the space dimension of the economy, but it can, equally, reflect the current habit of if adding adjectives to the substantive "development". The here displayed research allows to advance proposals that elapse of the debates on the trends of the space unbundling cidade/campo, on the space heterogeneidade of the economic dynamism and on the local initiatives that can be crucial for the development. It is looked, of this form, to establish the main relations of these debates with the evolution of the "regional planning". Key words: Regional planning; Innovative medium; Territorial development.

Resumen: Se observa, en general, el uso frecuente de la expresión "desarrollo territorial” o, algunas veces, "desarrollo spacial". Tal tendencia puede indicar un revaloriza1ción de la dimensión del espacio de la economía, pero puede reflejar, igualmente, el hábito actual de agregarse adjetivos al substantivo "desarrollo". La investigación aquí expuesta permite avanzar proposiciones decorrientes de las discusiones sobre las tendencias de la diferenciación espacial cidade/campo, sobre el heterogeneidade espacila del dinamismo económico y sobre las iniciativas locales que pueden ser cruciales para el desarrollo. Buscase, de esta forma, establecer las relaciones principales de estas discusiones con la evolución de la "planificación regional".

Palabras claves: Planificación regional; Medio innovador; Desarrollo territorial.

\section{Introdução}

Este texto investiga as motivações do emprego cada vez mais freqüente da expressão "desenvolvimento territorial" (por vezes "desenvolvimento espacial"). Seu principal objetivo é saber se tal tendência indica uma revalorização da dimensão espacial da economia, ou se, ao contrário, não passa de mais um prolongamento da infindável mania de se acrescentar adjetivos ao substantivo 'desenvolvimento'. A resposta também acabou sendo de natureza geográfica: "nem tanto ao céu, nem tanto à terra". Ou seja, parece estar havendo, de fato, uma revalorização da dimensão espacial da economia; mas tudo indica que tal evolução está longe de permitir que se considere a expressão "desenvolvimento territorial" como um conceito propriamente dito, além de ser muito cedo para conhecer seus efeitos práticos. Mesmo não podendo dar uma resposta mais original à referida pergunta, a investigação aqui exposta foi tão frutífera que permite avançar, a título de conclusões, dez proposições bem menos banais. Elas decorrem de uma exposição que está organizada em três partes.

A primeira aborda o debate sobre as tendências da diferenciação espacial cidade/ campo, mais concentrado entre pesquisadores de temas rurais. Trata-se essencialmente de uma crítica à tendência relativamente comum de se amalgamar desenvolvimento e urbanização, como fazem os que afirmam ser impossível que uma área rural se desenvolva sem que se torne automaticamente não-rural. A segunda aborda a heterogeneidade espacial do dinamismo econômico, mais concentrado entre estudiosos da "economia industrial". Ela examina a tortuosa evolução do debate internacional desencadeado pelos estudos sobre os distritos industriais marshallianos, que acabou dando respaldo científico à idéia do 'desenvolvimento local', isto é, de que as iniciativas locais podem ser cruciais para o desenvolvimento, pois se tornam importante fator de competitividade ao fazerem dos territórios ambientes inovadores. E a terceira procura estabelecer as principais relações desses dois debates com a evolução do "planejamento regional".

\section{Da "dicotomia" ao "continuum" rural- urbano}

Há quem acredite que o meio rural esteja sujeito a um processo de urbanização tão poderoso que a histórica contradição 
entre cidade e campo estaria fadada a desaparecer. Contudo, o que se verifica é a existência de três tipos de países desenvolvidos sob o prisma da diferenciação espacial entre áreas rurais e urbanas. Primeiro, um pequeno grupo fortemente urbanizado, que reúne Holanda, Bélgica, Reino Unido e Alemanha, no qual as regiões essencialmente urbanas ocupam mais de $30 \%$ do território e as regiões essencialmente rurais menos de $20 \%$, sendo que as intermediárias variam entre $30 \%$ e $50 \%{ }^{1}$. No extremo oposto há um grupo maior, formado por quatro países do "Novo Mundo" - Austrália, Canadá, Estados Unidos e Nova Zelândia - mas do qual também fazem parte três nações muito antigas: Irlanda, Suécia e Noruega. Nesse grupo as regiões essencialmente rurais cobrem mais de $70 \%$ do território e as relativamente rurais têm porções inferiores a $20 \%$. Finalmente, no caminho do meio, encontram-se França, Japão, Áustria e Suíça, países nos quais entre $50 \%$ e $70 \%$ do território pertence a regiões essencialmente rurais e cerca de $30 \%$ a regiões relativamente rurais.

Qualquer esforço para interpretar os fundamentos desses três padrões de diferenciação espacial do mundo desenvolvido será forçosamente levado a considerar fatores naturais objetivos, como o relevo, clima e hidrologia. Rejeitar explicações baseadas no determinismo natural não significa que se possa admitir o puro e simples possibilismo, isto é, a desconsideração de limites físicos e biológicos à ação humana na formação dos espaços rurais e urbanos, eludindo, assim, toda a problemática do relacionamento entre as sociedades humanas e os meios ditos naturais ${ }^{2}$. Além disso, foi justamente o avanço das pesquisas científicas em urbanismo que fez emergir o conceito de "ecossistema territorial", entendido como o espaço sem o qual um ecossistema urbano não pode exercer o conjunto de suas próprias funções vitais. Se o ecossistema territorial é composto tanto de elementos do ambiente físicobiológico, quanto do ambiente construído e do ambiente antrópico, torna-se impossível, então, recusar todo e qualquer tipo de determinismo geográfico para explicar a localização das atividades e das populações, como pretendiam os primeiros teóricos da economia espacial ${ }^{3}$.
Nada disso impede, entretanto, que seja muito atraente a crença de que o destino do espaço rural será seu desaparecimento por força de avassaladora urbanização. Para seus adeptos, a oposição cidade-campo já seria, inclusive, uma questão inteiramente superada, uma vez que a ruralidade não passaria de mero sucedâneo de uma formação social anterior, condenada pura e simplesmente a sumir, a exemplo do que já teria ocorrido na Holanda, essa vasta metrópole urbana apenas recortada por corredores verdes onde se misturam espaços recreativos e terrenos de uso agrícola. A idéia chegou a ser formulada nesses termos pelo secretário geral do Observatório Internacional de Prospectiva Regional, na abertura de um colóquio recentemente patrocinado pelo Senado francês.

Acontece, contudo, que essa visão de convergência para um suposto padrão holandês, de grande metrópole esverdeada, não resiste a qualquer tentativa de se encontrar homogeneidade espacial entre os países mais desenvolvidos, mesmo que se admita o reducionismo de considerar apenas os aspectos demográficos da questão. Um dos países desenvolvidos mais densamente povoados - a Suíça - tem $13 \%$ de sua população em regiões essencialmente rurais, $25 \%$ em regiões relativamente rurais e $62 \%$ em regiões essencialmente urbanizadas. Estendendo-se por largas partes do Jura, da Plaine e dos Alpes, as zonas rurais contribuem de maneira significativa à economia nacional, para não falar da imagem do país no exterior. E suas funções de residência, trabalho e lazer são consideradas essenciais por suas elites.

É verdade que só uma ínfima parte dos habitantes de meia dúzia de países do oeste europeu reside em regiões essencialmente rurais. Mas o peso das populações nas regiões relativamente rurais dessa seleta meia dúzia de países varia de $15 \%$ na Holanda a $44 \%$ na Itália. Nesta última, como no Japão, não chegam a $50 \%$ os habitantes de regiões essencialmente urbanas, mesmo que $70 \%$ residam em localidades urbanas. Em países maiores, como a França e o Canadá, apenas $29 \%$ e $44 \%$ dos habitantes estão em regiões essencialmente urbanas, mesmo que $60 \%$ residam em localidades urbanas. De resto, a 
diferenciação rural/urbana pode ser muito parecida em territórios tão diferentes quanto o da França e o dos Estados Unidos.

São bem diversas as combinações entre os vários tipos de atividade econômica que permitem elevar os níveis de renda, educação e saúde de muitas populações que continuam rurais. As novas fontes de crescimento das áreas rurais estão principalmente ligadas a peculiaridades dos patrimônios natural e cultural, o que só reafirma o contraste entre os contextos ambientais do campo e da cidade. Enfim, a visão de uma inelutável marcha para a urbanização como única via de desenvolvimento do campo só pode ser considerada plausível por quem desconhece a imensa diversidade que caracteriza as relações entre espaços rurais e urbanos dos países que mais se desenvolveram. Não faz sentido, portanto, amalgamar desenvolvimento e urbanização, como propõem sem rodeios os que dizem ser impossível que uma área rural se desenvolva sem que se torne automaticamente não-rural ${ }^{4}$.

Estão justamente entre as menos urbanizadas as microrregiões rurais dos Estados Unidos que hoje desfrutam das melhores perspectivas de desenvolvimento. São principalmente as do sul e do oeste que dispõem de clima agradável, montanhas, lagos, praias, podendo atrair muitos aposentados, turistas, excursionistas, esportistas, etc. Além desses condados já escolhidos por migrantes de alta renda, há muitos outros, principalmente no oeste, nos quais a forte incidência de terras federais faz com que seu futuro esteja estreitamente vinculado à evolução das políticas governamentais relativas ao meio ambiente, ao turismo e outros ramos recreativos. De resto, elevadas rendas per capita ocorrem nos condados rurais das Grandes Planícies, porque ali os serviços vinculados a atividades agroindustriais engendraram baixíssimos níveis de densidade demográfica. E há muita incerteza sobre as perspectivas socioeconômicas de condados rurais da metade oriental do país, principalmente no sudoeste, onde os serviços se combinaram a outros tipos de atividades industriais ${ }^{5}$.

Na prática, as desigualdades internas às regiões rurais de um mesmo país podem ser muito mais significativas que as referentes ao contraste rural/urbano. Em mais de um terço dos condados rurais dos Estados Unidos (795/2288), pelo menos $20 \%$ da população encontrava-se abaixo do nível de pobreza em 1990; um problema de difícil solução em 535 deles, quase todos concentrados no sudeste e no sudoeste, mas também presentes nos Appalaches e em algumas reservas indígenas do norte e do oeste. Todavia, mais de $80 \%$ da população rural americana reside em condados que conseguiram desenvolver sistemas produtivos cada vez mais baseados em vários tipos de combinações de atividades terciárias com as duas outras categorias setoriais. Para o conjunto dos espaços rurais dos Estados Unidos, as novas fontes de crescimento e emprego estão nas atividades de serviços ligadas ao lazer, à aposentadoria e ao meio natural, mesmo que continuem muito importantes outros tipos de serviços, como os financeiros, de seguros, imobiliários, de comércio varejista, de restauração, de lavagem a seco, etc.

Enfim, as áreas rurais dos países avançados que permanecem subdesenvolvidas são aquelas que não lograram explorar qualquer vocação que as conecte às dinâmicas econômicas de outros espaços - sejam eles urbanos ou rurais - e não aquelas que teriam sido incapazes ou impossibilitadas de se urbanizar. E como as novas fontes de crescimento econômico das áreas rurais estão principalmente ligadas a peculiaridades do patrimônios natural e cultural, intensificase o contraste entre campo e cidade

Tudo isso quer dizer, então, que a desacreditada abordagem "dicotômica" deveria ser reabilitada? Estaria sendo contrariada a abordagem inversa, de "continuum"? Depende muito, na verdade, do significado que se atribua a esses vocábulos ${ }^{6}$. De qualquer forma, o que não parece existir é qualquer evidência de que esteja desaparecendo a histórica contradição entre cidade e campo, inclusive no caso holandês, onde os espaços rurais tendem a ser caracterizados como meros corredores nos quais convivem atividades agrícolas e recreativas. Em outras palavras, há uma falsa alternativa sendo proposta nesse duelo entre dicotomia e "continuum". Mas para disso se dar conta, é absolutamente necessário sair do isolamento demográfico (ou no máximo sociológico) em que foi metido esse debate, como se seus 
fundamentos ecológicos e econômicos tivessem menor importância.

O desafio é, portanto, entender as várias dinâmicas socioeconômicas, das mais efêmeras às mais duráveis, distinguindo bem as reversíveis das irreversíveis, pois algumas podem ser duráveis sem que sejam necessariamente irreversíveis. Ninguém ignora que a proporção das atividades primárias nas economias mais desenvolvidas caiu, neste século, de metade para um vigésimo. Enquanto isso, as terciárias subiram de um quarto para mais de três quintos, e as secundárias deslizaram de pouco mais a pouco menos de um terço. Só que os resultados dessas grandes tendências foram bem heterogêneos. Entre os países do primeiro mundo, a parte dos serviços varia de $50 \%$ a $70 \%$, a das industriais de $40 \%$ a $25 \%$, e a das primárias de $10 \%$ a $3 \%$ dos ocupados.

Mais heterogêneas ainda foram as repercussões espaciais dessa enorme mudança estrutural. $\mathrm{O}$ fato de atividades primárias estarem forçosamente muito mais presentes nas zonas rurais não significa que os outros dois tipos sejam necessariamente muito mais recorrentes nas zonas urbanas. $\mathrm{O}$ emprego industrial é mais significativo nas regiões relativamente rurais que nas essencialmente urbanas, chegando mesmo a ser muito mais rural que urbano em países nórdicos, como a Noruega e a Suécia. E os serviços têm quase o mesmo peso em regiões essencialmente urbanas e relativamente rurais, sendo extraordinariamente importantes nas regiões essencialmente rurais da Bélgica.

Não é portanto a composição setorial das economias desenvolvidas que pode explicar o surgimento, no final do século $X X$, de indícios opostos à chamada "desertificação rural" que estariam anunciando um certo "renascimento rural". Essa hipótese foi contrariada pelos estudos da OCDE que compararam as regiões rurais mais dinâmicas às mais letárgicas ou decadentes. Os resultados mostram que o melhor desenvolvimento de determinadas zonas rurais tem causas ainda desconhecidas, mas que, com certeza, não estariam relacionadas a diferenças em suas respectivas estruturas setoriais.

Ora, foi justamente a vontade de entender quais seriam as fontes geradoras do maior dinamismo econômico de certas loca- lidades que desencadeou tantas discussões sobre as virtudes dos distritos industriais marshallianos para o desenvolvimento; um longo debate que acabou dando origem aos amplos programas de pesquisa sobre relações das mais diversas entre mutações econômicas e recomposições espaciais.

Foi a identificação de "constelações econômicas localizadas que venciam a recessão" em áreas relativamente rurais como a Toscana e Emilia-Romagna (Itália), Baden-Württemberg (Alemanha), Cambridge (Inglaterra), Smäland, (Suécia), e até essencialmente rurais, como WestJutdland (Dinamarca), que levou um grupo de pesquisadores ligados à OIT a se perguntar, em meados dos anos 1980, se essa virtuosa combinação entre eficiência e altos níveis de emprego poderia se tornar um modelo para outras regiões.

Idêntica interrogação estava no centro das preocupações que levaram à formação simultânea do Grupo Europeu de Pesquisas sobre os Ambientes Inovadores (Gremi), que se propunha a entender os processos coletivos de aprendizagem. Os desdobramentos do amplo debate que se seguiu foram evidenciando os limites da noção de "distrito", fazendo com que paulatinamente fosse dada preferência à noção mais ampla de "sistemas produtivos locais (SPL)" ("Local Productive Systems").

\section{Do "distrito marshalliano" ao localismo}

Muitas controvérsias foram se misturando ao debate desencadeado pelos pioneiros estudos italianos ${ }^{7}$, como evidenciam as revisões críticas publicadas em quatro espessas coletâneas sobre o assunto ${ }^{8}$. E os resultados dessa vasta produção científica ainda não explicam satisfatoriamente as razões do maior ou menor dinamismo econômico de cada território, dificultando muito qualquer tentativa de síntese. De qualquer forma, assim que algumas lições gerais sobre os "distritos" começaram a ser tiradas, foram também surgindo muitas dúvidas sobre a possibilidade de que elas pudessem vir a ser aproveitadas em contextos muito diferentes. No caso italiano, por exemplo, constatou-se uma fortíssima correlação entre a distribuição espacial da economia "difusa", que caracterizava suas províncias mais dinâ- 
micas, e a intensidade das formas familiares de agricultura (e portanto de razoável distribuição de renda). Além disso, a organização municipal específica do Centro-Norte da Itália, cuja origem remonta à Idade Média, mostrou que essas comunidades locais haviam estabelecido há muito tempo uma boa divisão territorial do trabalho entre cidade e campo, uma organização muito articulada da sociedade urbana, e uma rede muito densa de comunicações.

Em áreas como o Mezzogiorno, historicamente fundadas em formas patronais de agricultura, não existe a mobilidade e a articulação social que engendram a criação de um grande número de flexíveis PMEs. Também não existe essa organização espacial que permite evitar uma fratura entre cidade e campo. Como enfatiza o economista industrial italiano Gioacchino Garofoli, não se trata de um processo com vocação a ocorrer em qualquer lugar, pois está ligado a alguns pré-requisitos da própria formação socioeconômica de cada território9 .

Mas se as heranças institucionais de uma economia baseada na agricultura familiar são condições necessárias, elas estão muito longe de ser suficientes. Para que muitas empresas e muitos empregos possam ser criados em regiões não privilegiadas pela velha obsessão de "pólos" ou "eixos" urbanoindustriais, também é preciso que elas disponham de um mínimo de condições favoráveis em termos de comunicações e de serviços e, sobretudo, de condições que estimulem o "empreendedorismo". Afinal, são os empreendedores os principais agentes da mudança econômica, pois são eles que geram, disseminam e aplicam as inovações. Ao procurarem identificar as potenciais oportunidades de negócios e assumirem os riscos de suas apostas, eles contribuem tanto para um maior uso dos recursos disponíveis, quanto para a expansão das fronteiras da atividade econômica. Mesmo que muitos não tenham sucesso, é sua existência que faz com que uma sociedade tenha constante geração de novos produtos e serviços.

Infelizmente, não se sabe muito bem quais são os determinantes do "empreendedorismo", apesar de sua crucial influência sobre o crescimento econômico. Sequer existe acordo sobre os indicadores que melhor reve- lariam os graus relativos em que o fenômeno se manifesta. É sabido, entretanto, que ele também nunca ocorre de forma homogênea entre as regiões de uma mesma nação. Comparando-se extremos, percebe-se que em certas regiões da Alemanha surgem mais do que o dobro de novas firmas do que em outras. A mesma relação se aproxima do triplo na Itália, na Suécia e no Reino Unido, chegando a girar em torno do quádruplo na França e nos Estados Unidos ${ }^{10}$.

Tudo indica que essas divergências espaciais da criatividade empreendedora correspondem ao chamado fenômeno de "clustering" (formação de "feixes" ou "cachos"). Segundo uma das definições mais aceitas, "cluster" é uma concentração geograficamente delimitada de negócios independentes que se comunicam, dialogam e transacionam para partilhar coletivamente tanto oportunidades quanto ameaças, gerando novos conhecimentos, concorrência inovadora, chances de cooperação, adequada infra-estrutura, além de freqüentemente também atraírem os correspondentes serviços especializados e outros negócios correlacionados. E os estudos sobre a relação existente entre a formação desses feixes e o "empreendedorismo" acabam sempre por enfatizar os fatores culturais que às vezes são compactados na sedutora noção de "capital social": um complexo de instituições, costumes e relações de confiança que geram a "atmosfera" necessária a seu estímulo ${ }^{11}$.

São muito ilustrativas as conclusões dos balanços feitos em paralelo pelo suíço Denis Maillat e pelo italiano Giacomo Becattini, respectivamente fundador do Gremi e principal expoente dos distritólogos ${ }^{12}$. As abrangentes pesquisas empíricas do Gremi levaram Maillat a concluir que os ambientes inovadores (milieux innovateurs) se manifestam em condições territoriais e produtivas das mais diversas: podem ser especializados ou multifuncionais, industriais e turísticos, urbanos e rurais, de alta tecnologia ou de tecnologia tradicional. Dá para afirmar quais são as mudanças possíveis e identificar empiricamente as que já estão em curso. Mas não se sabe o que realmente faz com que determinado território seja capaz de gerar um novo modo de organização e de produção.

A principal conclusão de Becattini é que uma política industrial só pode ser 
sistemática e racional se estiver apoiada num tableau das relações socioeconômicas "historicamente determinadas", isto é, numa representação da trama de sistemas produtivos locais que não isole as relações técnico-econômicas das relações socioculturais e institucionais, como faz a matriz input-output. A revisão dos estudos e debates sobre os distritos industriais marshallianos acabaram por convencê-lo de que os verdadeiros recursos críticos de uma economia nacional são os sistemas locais: organismos de formação lenta e difícil, que constituem um patrimônio a ser reconhecido, conservado e fortificado. Assim, para superar a ignorância reinante sobre a importância dos SPL, Becattini considera necessária a adoção de uma estratégia de pesquisa com três linhas de orientação: a) redefinição de uma grande parte do aparato teórico da economia e de outras ciências sociais; b) trabalho de campo que explore as similaridades e diferenças e não evite as conexões entre fenômenos que pertencem a campos disciplinares diversos; c) uma caracterização atenta dos SPL, na linha de trabalho explorada por seu colega Fabio Sforzi ${ }^{13}$.

O principal mérito de Sforzi foi tentar superar as distorsões impostas pelo uso das fronteiras de caráter político-administrativo como unidade espacial de análise. Afinal, apenas uma parte das localidades pertencentes às províncias que formavam a famosa "Terceira Itália" tinham o dinamismo da economia "difusa" presentes em distritos marshallianos. Além disso, fenômeno idêntico também ocorria no noroeste ("Primeira Itália"). Era portanto necessário encontrar uma unidade espacial de análise empírica que não fosse tão distante dos marcos conceituais das análises econômicas de Giacomo Becattini, Sebastiano Brusco ou Gioacchino Garofoli e das abordagens sociológicas de Arnaldo Bagnasco, Carlo Trigilia ou Vittorio Capecchi. A contribuição de Fabio Sforzi foi justamente a de tomar o "sistema de localidades interligadas" como padrão espacial de análise do processo de industrialização e do desenvolvimento socio-econômico em geral.

A base do argumento é que o desenvolvimento ocorre localmente quando uma indústria e uma população têm a mesma área comum de interação social e econômica.
Isso acontece em todo tipo de localidade, desde as de tipo mono-industrial até as marcadas por uma grande quantidade de pequenos negócios mais ou menos similares. O que as diferencia é a maneira pela qual as firmas e a população estão envolvidas na divisão do trabalho. Uma regionalização funcional da Itália - feita a partir de dados censitários de 1981 sobre os fluxos de deslocamento entre residência e trabalho (journeyto-work flows) - permitiu a identificação de 955 Áreas de Mercado de Trabalho Local (LLMAs: Local Labour Market Areas), que foram agrupadas em 15 tipos de sistemas locais mediante uma análise de suas estruturas socioeconômicas.

Essa importante contribuição de Sforzi foi, infelizmente, distorcida pela divisão setorial. Sua principal motivação era comparar os 61 distritos industriais marshallianos (como os de Carpi e Prato), enquanto subcategoria das 161 LLMAs de industrialização leve, a outros três tipos: a) as 76 LLMAs do norte e do centro dominadas por indústrias e serviços (como as de Milão e Florença); b) as 64 LLMAs do sul, dominadas principalmente pelos serviços (como as de Nápoles e Palermo); e c) as 96 LLMAs industriais do norte (como as de Lumezzane e Valdagno).

Ao selecionar as categorias que considerou "comparáveis", Sforzi misturou todos os sistemas locais extra-urbanos baseados no turismo ou em atividades consideradas "semi-rurais" ou "rurais". Pior, essas nove categorias extra-urbanas foram atiradas numa mesma gaveta com as "marginais" e as "deprimidas" do sul. Assim, 11 tipos de sistemas locais - reunindo 558 das 955 LLMAs - foram amalgamados na única categoria considerada "residual" e denominada "Resto da Itália".

Ora, quando se examina com atenção as tabelas organizadas para fazer essa comparação, percebe-se que no período considerado - 1971/81 - a categoria "Resto da Itália" gerou proporcionalmente mais empregos no agregado do que qualquer uma das outras quatro, embora sempre tenha sido superada por alguma delas em quase todas as divisões setoriais específicas. Ou seja, sem pretender, essa contribuição de Sforzi é uma excelente ilustração do potencial gerador de empregos que também existe em sistemas 
locais extra-urbanos e menos especializados. Reforça a hipótese de que nesses sistemas locais extra-urbanos e extra-industriais podem existir efeitos sinérgicos de geração de empregos comparáveis até aos que se manifestam nessa espécie de vanguarda constituída pelos distritos industriais marshallianos. Mas como eles foram todos embutidos numa única e extremamente heterogênea categoria, formada por $60 \%$ das Áreas de Mercado de Trabalho Local, incluindo até as duas mais "deprimidas" e as 41 "marginais", fica impossível separar "o joio do trigo".

Esse forte viés "industrialista" foi mantido na atualização feita com os dados censitários de 1991, apresentada na conferência sobre "Sistemas Locais de Pequenas Empresas e Criação de Emprego", organizada pela OCDE em junho de $1995^{14}$. Os sistemas locais sem concentração de emprego fabril foram outra vez empacotados numa categoria "residual", desta feita denominada "nãoindustrial". O resultado ficou ainda mais estranho, pois nos anos 1980 houve redução generalizada do emprego no setor industrial, em flagrante contraste com seu aumento no setor terciário, particularmente entre as empresas de "serviços não-tradicionais". E a inevitável conclusão foi, evidentemente, a de enfatizar que, "no mundo real", as fronteiras entre a indústria e os serviços estão sendo progressivamente removidas...

Os trabalhos apresentados na referida conferência da OCDE marcaram uma clara ruptura com a tendência anterior de atribuir apenas à indústria a glória pelo bom desempenho econômico de determinadas áreas geográficas. Os participantes preferiram chamar a atenção para as ligações entre as empresas em geral e sua capacidade de criar redes ("business links and networking") ou, de maneira ainda mais abrangente, para os sistemas locais de PMEs ("local systems of $\left.S M E s^{\prime \prime}\right)$. E própria idéia de "distrito" chegou a ser completamente "desindustrializada" na contribuição holandesa sobre o "distrito floricultor de Keukenhof' ("the flowergrowing district of Keukenhof").

Pode-se dizer, portanto, que a redescoberta da noção marshalliana de "distrito" foi certamente muito enriquecedora, mas que ela não pode dar conta da complexidade e diversidade dos sistemas locais. Ao mesmo tempo, precisa ser evitado o risco de serem criadas tantas novas noções quantas forem as situações diferenciadas. Daí a vantagem da noção de "sistemas produtivos locais" ("local productive systems") que acabou, aliás, entrando no subtítulo da publicação dos anais dessa conferência da OCDE sobre "Sistemas Locais de Pequenas Empresas e Criação de Emprego".

Nos Estados Unidos, $60 \%$ das atividades econômicas puderam ser atribuídas a um total de 380 "clusters" em diversas fases de amadurecimento, e depois classificados em apenas quatro tipos de origens: a) recursos naturais estratégicos, como nos casos de Chicago (agroalimentar); b) fontes de novas tecnologias, como o Vale do Silício (microeletrônica); c) mercados de trabalho especializado, como Dalton, na Georgia (tapetes) ou Tupelo, no Mississippi (móveis); e d) oportunidades mercadológicas, como Buffalo, em New York (meio ambiente), ou mesmo New York City (jóias).

Todos os que procuraram entender qual é a relação existente entre a formação desses feixes e o empreendedorismo acabaram por enfatizar os mesmos fatores culturais presentes em todas as caracterizações de "distritos" ou "SPL". Como já foi dito, a única diferença é que esses fatores culturais são muitas vezes compactados na sedutora noção de "capital social", relançada com muita perspicácia pelas pesquisas coordenadas por Robert Putnam sobre as diferenças de desempenho institucional das diversas províncias da Itália. Muitas vezes, o capital social é entendido como um complexo de instituições, costumes e relações de confiança que alavancam a cooperação. Outras vezes, essa expressão "capital social" é expressamente evitada e substituída por longas considerações sobre misteriosos processos formadores de atitudes culturais que afetam não somente a disposição a cooperar com outros, mas, sobretudo, as estruturas institucionais que influenciam o empreendedorismo.

Uma excelente síntese da questão foi feita por Sebastiano Brusco ao apontar as três lições essenciais que devem ser tiradas da experiência italiana: a) a necessidade de combinar concorrência com cooperação; b) a necessidade de combinar conflito com parti- 
cipação; e c) a necessidade de combinar o conhecimento local e prático com o científico. Essas três lições fazem com que a interrogação central passe a recair, portanto, sobre as condições que permitem a emergência de instituições mais favoráveis a essas três combinações. E a resposta - como não poderia deixar de ser - é afirmação de que o desenvolvimento depende essencialmente do papel catalisador que desempenha um projeto elaborado por atores locais.

Nota-se, portanto, que nessa tortuosa evolução do debate internacional desencadeado pelos estudos sobre os distritos industriais marshallianos, ganhou forte respaldo científico uma perspectiva contrária à que predominou durante muito tempo nas esferas governamentais e nas organizações internacionais que procuram influenciar os rumos das políticas econômicas nacionais.

Com muito atraso, estas começaram a levar a sério proposições sobre desenvolvimento "endógeno", desenvolvimento "de baixo para cima", e até sobre "ecodesenvolvimento" ${ }^{15}$, acabando por admitir que as iniciativas locais podem ser cruciais para o desenvolvimento, pois se tornam importante fator de competitividade ao fazerem dos territórios ambientes inovadores. Evidentemente, não demoraram tanto a aparecer as limitações inerentes às resultantes políticas do "desenvolvimento local", o que acabou por estimular debates dos mais bizantinos sobre as relações entre o "local" e o "global" no processo de desenvolvimento, nos quais costumam até a se levar a sério ridículas disputas entre o "glocalismo" e o "lobalismo"...

\section{Do planejamento regional ao desenvolvimento territorial}

Durante a "era de ouro" (1948-73), a preocupação de minorar as distorções espaciais fatalmente provocadas pelo crescimento econômico levou à montagem de estruturas administrativas cuja principal missão seria a de "planejar" ou "ordenar"o povoamento (ou ocupação) de territórios nacionais mediante determinadas orientações de investimentos públicos em infra-estrutura e várias formas de incentivos e regulamentações sobre os investimentos privados. Surgiram então vários tipos de arranjos adminis- trativos nacionais de "planejamento regional" (ou "ordenamento territorial"), que não podiam se basear em qualquer experiência acumulada em países capitalistas. As raras tentativas anteriores haviam sido todas restritas a uma determinada região, além de pertencerem ao contexto inverso, isto é, o da contração da economia mundial durante o entre-guerras. Foi nos anos 1930 que a experiência do New Deal com a TVA (Tennessee Valley Authority) incentivou o governo britânico a dar um tratamento diferenciado a suas áreas de mineração muito afetadas pela crise, e estimulou o governo italiano a adotar medidas que pudessem reduzir a miséria do Mezzogiorno. Antes disso houve imenso desprezo pelo fator espacial, tanto nas políticas econômicas, quanto na ciência na qual pretendem se inspirar. No capitalismo anterior a 1929, talvez só possam ser citadas as propostas dos saint-simonianos e a obra teórica de Von Thünen como as exceções que confirmam a regra.

Duas reações ao "marasmo" econômico que se seguiu à "era de ouro", a partir dos anos 1970, pressionaram muitos desses recentes aparatos de planejamento (ou ordenamento) a redefinir sua missão. Uma delas foi a forte vaga de "descentralização" baseada na idéia de que as distorções que produziam as disparidades regionais desapareceriam por si só, caso as administrações locais tivessem mais liberdade, poder e meios de ação. Outra foi o impulso para uma maior integração supra-nacional, que se manifestou principalmente no oeste europeu, mas que vem tendo desdobramentos semelhantes em outras regiões dos continentes americano e asiático. E foi como resultado dos mais evidentes dessa dupla pressão que se deu o deslize semântico para "desenvolvimento espacial" e, principalmente, para "desenvolvimento territorial".

As vantagens das palavras "espaço" e "território" são evidentes: não se restringem ao fenômeno "local", "regional", "nacional" ou mesmo "continental", podendo exprimir simultaneamente todas essas dimensões. A UE vinha elaborando há quatro anos sua "perspectiva" ou "esquema" de "desenvolvimento espacial"16, quando a OCDE criou um novo serviço com a missão de levar seus países membros a elaborar suas próprias con- 
cepções de "desenvolvimento territorial"17. Muito mais significativas, entretanto, parecem ser as motivações que levaram ao progressivo uso do substantivo "desenvolvimento" para substituir os fora de moda "planejamento" e "ordenamento".

Na França, foi uma comissão interministerial "de ordenamento do território" que preparou um projeto de lei de orientação "para o desenvolvimento do território". Tal fato é considerado marco simbólico de uma virada, mesmo que do debate parlamentar tenha resultado, em 4 de fevereiro de 1995, uma lei que acabou conservando os dois vocábulos ("l'aménagement et le développement $d u$ territoire"). Basicamente porque o ordenamento seria algo "consentido, outorgado e redistribuitivo", enquanto o desenvolvimento seria "desejado, partilhado e produtor de riquezas". Ou ainda, porque se pretende cruzar, num mesmo espaço, uma política "descendente (ordenamento) com uma política ascendente (desenvolvimento)"18.

A "perspectiva" européia de desenvolvimento espacial (UE/ESDP) tem dois objetivos essenciais: aumentar a capacidade competitiva de territórios cuja integração no processo concorrencial é inadequada, e limitar os efeitos negativos de uma concorrência exacerbada. Nos dois casos, a abordagem espacial procura uma melhor combinação entre competição e cooperação, de forma que o conjunto do território europeu possa atingir um nível ótimo de competitividade, reforçando, ao mesmo tempo, sua coesão econômica e social. Para atingir esses objetivos, os meios foram agrupados em três conjuntos operacionais: a) um sistema policêntrico de cidades, com uma nova relação urbano/ rural; b) uma paridade de acesso à infraestrutura e ao conhecimento; c) uma gestão mais prudente das heranças natural e cultural $^{19}$. Para tanto, os vetores do desenvolvimento espacial europeu ${ }^{20}$ foram triados em termos de forças, fraquezas, oportunidades e ameaças ("SWOT analysis") sendo identificado um conjunto de 13 principais tendências (3 demográficas, 4 econômicas e 6 ambientais), destacando-se o fato da economia e do emprego europeus se tornarem cada vez mais dependentes das pequenas e médias empresas (PMEs) como a mais importante das tendências econômicas.
Uma das principais ambições do ESDP é tornar mais coerentes as quatro políticas comunitárias de "significativo impacto espacial" que foram substancialmente fortalecidas, em 1992, tanto pelo Tratado de Maastricht, como pelo subseqüente Conselho Europeu reunido em Edinburgh: a) a agrícola (PAC), reformada nesse mesmo ano; b) a dos "Fundos Estruturais", ao qual foi juntado o novo "Fundo de Coesão"; c) a de transportes e comunicações, agrupadas sob a sigla "TENs" ("TransEuropean Networks"); e d) a política ambiental.

O serviço de desenvolvimento territorial da OCDE só foi criado por seu Conselho no início de 1994, quase um ano depois da apresentação formal do projeto pelo Secretário Geral. Com o firme apoio da representação austríaca, ele propôs o agrupamento de quatro unidades até ali dispersas em outras divisões: os grupos especializados em questões urbanas, desenvolvimento rural e desenvolvimento regional, mais o programa de ação e cooperação sobre iniciativas locais de criação de emprego ${ }^{21}$. Baseou tal proposta em duas justificativas, uma de ordem política e outra de ordem operacional:

a) As zonas urbanas, suburbanas e rurais são cada vez mais interdependentes e os problemas de uma delas também interferem nas outras. Por exemplo, os fenômenos de aglomeração e de congestão urbana são inseparáveis da debilitação de certas regiões e do êxodo rural. Além disso, os efeitos de proximidade tornam ainda mais manifesta a necessidade de uma abordagem política coordenada, que possa integrar o conjunto dos aspectos do desenvolvimento. Assim, na escala local, os problemas de emprego, de harmonia social, de qualidade da vida - para tomar apenas alguns exemplos são indissociáveis [...].

b) $\mathrm{O}$ desenvolvimento harmônico do tecido econômico está no centro dos trabalhos dos grupos que tratam de assuntos urbanos, locais, rurais e regionais. Isso se traduz por ações que visam encontrar, para uma determinada zona, um equilíbrio entre o fortalecimento de sua capacidade concorrencial e melhoria da qualidade de vida de seus habitantes. Atingir esse objetivo exige a criação de novas formas de parcerias entre os atores envolvidos, quer eles sejam públicos, privados, nacionais, regionais ou locais. Estímulo a projetos, iniciativa rural, ação urbana, tudo isso decorre da mesma idéia, segundo a qual as contribuições locais permitem operar mudanças significativas na paisagem socioeconômica territorial $^{22}$.

Durante o primeiro debate dessa proposta, três outras delegações - Austrália, Canadá e Noruega - juntaram-se à da Áustria 
para considerar o novo serviço como "primeira etapa lógica" de um processo que deveria permitir à OCDE uma abordagem analítica mais horizontal das questões relativas ao desenvolvimento econômico, social e ecológico de seus países membros. Em seguida, as delegações da Holanda e da Suíça foram ainda mais longe, chegando a propor, inclusive, a "completa fusão dos órgãos subsidiários dos quatro grupos". Mas tanto entusiasmo esbarrou na resistência das delegações do Japão, da Bélgica e do Reino Unido, e numa certa hesitação por parte dos representantes da Irlanda e da Espanha. Muitas dessas reticências eram de ordem orçamentária, mas também foi mencionado o temor de que o novo serviço viesse a reforçar a concentração da OCDE em "questões de desenvolvimento econômico e industrial em detrimento dos problemas ambientais, do turismo e da cultura" ${ }^{23}$. Como tais "dúvidas" não foram completamente superadas, elas voltaram a se manifestar em 1998. Mas, até o momento, nada disso alterou a natureza do "TDS", que continua a ser apresentado da seguinte forma:

Fatores espaciais são elementos importantes na 'real' organização da atividade econômica, mas continuam fora do escopo dos atuais macro referenciais. Esses dois mundos - o dos gestores da política macroeconômica e o das localidades, cidades e regiões - continuam bem independentes um do outro, mesmo quando muitas questões consideradas 'locais' têm revelado um caráter cada vez mais 'transfronteiriço'. De resto, distorções econômicas e sociais continuam a afetar a alocação espacial de recursos e de renda - assim como o papel do setor público - não podendo, portanto, ser ignoradas pelas abordagens mais gerais sobre o crescimento e o ajuste estrutural.

Contra esse tipo de herança, a OCDE reforçou seu trabalho sobre as relações entre políticas governamentais de caráter urbano, rural, regional e local, mediante o agrupamento dessas atividades em um único Serviço de Desenvolvimento Territorial. Uma preocupação central é entender como as políticas desses quatro núcleos relacionados ao espaço podem efetivamente contribuir para reformas estruturais e funcionamento das forças de mercado, e particularmente para a capacidade de geração de empregos produtivos, de adequado aproveitamento de recursos humanos, de melhoria do padrão e da qualidade de vida, de resposta à crescente demanda de amenidades, e de prevenção contra a marginalidade social e a degradação ambiental; enfim, todos os componentes indispensáveis ao bom funcionamento das localidades, cidades e regiões ${ }^{24}$.
Um dos fatores que fez brotar no interior da OCDE a idéia de juntar sob o lema do "desenvolvimento territorial" seus núcleos voltados aos problemas urbanos, rurais e regionais foi, com certeza, mais de um decênio de experiência com o programa dedicado à geração de empregos mediante estímulos ao "desenvolvimento local". Esse programa de ação e cooperação sobre iniciativas locais de criação de emprego - que hoje se chama “LEED - Local Economic and Employment Development" - foi criado em 1982, e deu origem a uma vasta rede de intercâmbio que divulga análises e relatos de experiências concretas por meio de "notebooks" e de uma "newsletter" intitulada Innovation $\mathcal{E}$ Employment, que chegou a ser editada em parceria com a União Européia.

Em maio de 1993, o comitê diretor desse programa decidiu fazer uma série de avaliações nacionais das políticas e práticas de desenvolvimento local. O foco desses estudos anuais deveria estar justamente nas relações entre as políticas nacionais, regionais e locais, de tal forma que se pudesse discutir a coerência dos programas de desenvolvimento local de cada país. O primeiro a se candidatar a esse tipo de avaliação foi o governo austríaco, numa iniciativa conjunta de sua 'Chancelaria Federal' e do seu 'Serviço de Mercado de Trabalho'. Além de quatro funcionários da OCDE e de dois representantes de países membros (Holanda e Canadá), o grupo de trabalho encarregado dessa avaliação contou com a colaboração de dois especialistas convidados: Michael Piore, do MIT e Alvaro Espina y Montero, assessor especial do Ministro da Economia da Espanha.

Como logo no início dos anos 1970 a Áustria foi drasticamente atingida pela crise do padrão de crescimento da "era de ouro", ela foi um dos primeiros países a experimentar as opções de "reestruturação industrial" discutidas no âmbito das organizações internacionais ao longo dos anos 1980, e que acabaram convergindo para a idéia central de promover o "desenvolvimento local". Isso teve um claro impacto no "Conceito Austríaco de Planejamento Regional", reelaborado a cada dez anos por uma "Conferência sobre Planejamento e Políticas Regionais (ÖROK)", presidida pelo chanceler federal 
e formada por vários ministros, governadores das Länder e representantes das comunidades locais. A principal diferença entre os "conceitos" de 1981 e de 1991 foi que o último não visa diretamente a redução das diferenças regionais de padrão de vida, nem a criação/atração de novas empresas em áreas menos favorecidas mediante incentivos financeiros. O texto de 1991 procurou, ao contrário, definir com clareza o potencial de cada região para um desenvolvimento "endógeno", dando origem, no âmbito federal, ao "Programa para o Desenvolvimento Regional Endógeno (FER)".

Ao tirar as lições da experiência austríaca de "ajustamento local à reestruturação industrial", o relatório do grupo avaliador da OCDE fez uma leve crítica a essa evolução, enfatizando que o grande perigo da abordagem do desenvolvimento local é a simples agregação de programas, sem uma estratégia que de fato possa mobilizar o conjunto das comunidades. Ou ainda, que “a estratégia de desenvolvimento local é particularmente válida como um complemento do desenvolvimento regional no âmbito de uma estratégia maior baseada no conceito de 'desenvolvimento territorial' - a combinação de políticas governamentais descendentes com iniciativas de desenvolvimento endógeno" 25 .

Outro fator que certamente contribuiu para que a OCDE decidisse criar um serviço de desenvolvimento territorial foi quase um decênio de experiência com o programa de desenvolvimento rural, particularmente o Projeto sobre Indicadores de Emprego Rural ("REMI Project"). Foi ele que deixou claro o quanto podem ser enganosas as comparações cronológicas de indicadores de emprego para uma mesma área, e o quanto podem ser instrutivas as comparações espaciais em um mesmo momento. Apesar da base estatística da OCDE ser uma das que melhor permite comparações entre países - isto é, territórios - até o início dos anos 1990 essa organização só dava atenção às séries temporais de cada país membro. No entanto, as diferenças cronológicas das taxas de desemprego, por exemplo, são muito menos significativas que as disparidades entre os países membros. Em 1995, essas taxas variavam de menos de $3 \%$ no Japão a mais de $23 \%$ na
Espanha. E as disparidades regionais dentro de cada país eram ainda mais importantes.

Também se deve ao REMI a demonstração de que o sucesso e o insucesso em criar novas oportunidades regionais de emprego não estão estritamente correlacionados aos graus de urbanidade ou de ruralidade. A ruralidade não é deficiência, e também não é sinônimo de declínio; tanto quanto urbanidade e aglomeração não garantem automaticamente um próspero desenvolvimento. Em vez de comparar apenas as diferenças entre áreas rurais e urbanas, tornando implicitamente o urbano como modelo para o rural, o REMI preferiu se dedicar a comparações entre regiões mais e menos dinâmicas. Principalmente porque as regiões rurais mais dinâmicas podem ser melhor referência para similares mais atrasadas do que o seriam as urbanas. E foi a partir desse tipo de comparações realizadas pelo REMI que o programa de desenvolvimento rural da OCDE passou a ganhar consistência.

O eixo dos poucos trabalhos sobre questões rurais feitos durante os anos 1980 era a necessidade de melhorar sua gestão pelos aparelhos de administração governamentais. Como a elaboração de políticas para o meio rural depende de um amplo e heterogêneo conjunto de entidades públicas, os principais desafios convergiam sistematicamente para a necessidade de realizar um trabalho cooperativo. Não é de se estranhar, portanto, que a palavra-chave dessa fase tenha sido "parceria". Nessa linha, diversas atividades que juntaram responsáveis nacionais pelas políticas de desenvolvimento rural com estudiosos do assunto, revelaram o quanto era precário o entendimento da imbricação dos problemas rurais com as mais amplas tendências socioeconômicas, ambientais e políticas. Isto é, a necessidade de uma "uma abordagem mais global, e inclusive territorial, da política rural" 26 .

Além disso, processos de reforma das políticas agrícolas estavam em curso em muitos países membros e, principalmente, na Comunidade Européia. Tudo isso certamente ajudou para que, em 1991, o Conselho da OCDE resolvesse criar um programa voltado especificamente para o fenômeno rural, tendo como primeira tarefa a elaboração de um relatório, só publicado em 1993 com o 
provocativo título "Que futuro para os nossos campos?" ("What Future for Our Countryside?", "Quel avenir pour nos campagnes?"). E talvez tenha sido justamente por mostrar a dificuldade de se encontrar respostas convincentes a essa grande interrogação, que esse trabalho tenha contribuído, não só para a criação do Serviço de Desenvolvimento Territorial, mas, sobretudo, para que se investisse em 'estudos de caso' e 'oficinas de trabalho' que pudessem trazer novos "insights", mesmo que não trouxessem conclusões generalizáveis.

Essa linha mais empírica de trabalho foi tão fecunda que torna impossível qualquer pretensão a uma síntese que lhe faça justiça. Mas há três pontos que não podem deixar de ser registrados: a) a matriz dos principais bens e serviços que aproveitam as vantagens competitivas do meio rural (que resultou de investigações sobre a equivocada noção de "nichos de mercado"); b) as razões da lentidão do processo de aproveitamento dessas vantagens competitivas; e, sobretudo, c) a crescente evidência de que estão nos patrimônios natural e cultural ("rural amenities" ou "aménités rurales") as principais vantagens competitivas dos espaços rurais.

Ao selecionar os estudos de caso, a ênfase recaiu sobre os bens e serviços que usam recursos mais freqüentes nas áreas rurais. Em seguida fez-se uma classificação segundo três características - recursos naturais, heranças culturais e tradicionais, e recursos ambientais - e dois critérios econômicos bens e serviços - da qual resultou uma "matriz" com seis janelas que ilustram muito bem a diversidade da economia rural. Depois foi feita uma lista dos oito obstáculos que mais dificultam um aproveitamento econômico mais rápido desses recursos, com ênfase especial para a distância que existe entre a realidade de formações sociais ainda "agrárias" e a própria natureza das modernas atividades de "marketing".

O que mais chama a atenção nas seis janelas da matriz da diversidade rural é que todas elas estão umbilicalmente ligadas ao aproveitamento econômico do que se convencionou denominar "amenidades". Ou seja, em sua etapa mais avançada, o desenvolvimento rural depende muito mais das possíveis maneiras de tornar rentável a preservação de peculiaridades naturais e culturais, do que da exploração dos velhos trunfos baseados na exploração da fertilidade dos solos, ou no aproveitamento de vantagens de localização industrial. E quando se consegue estabelecer uma sinergia entre preservação de "amenidades" e dinamismo econômico - como acontece, por exemplo, no caso da trilha de fronteiras suíça, ou no dos parques naturais franceses - fica simplesmente impossível dizer se a atividade é "primária", "secundária" ou "terciária".

A idéia de que os países membros da OCDE devem dar alta prioridade à capitalização do valor das "amenidades rurais" foi a principal conclusão da oficina de trabalho realizada em setembro de 1997 no Japão, na qual foram analisados estudos de caso referentes a doze países (Austrália, Áustria, Bélgica, Canadá, Finlândia, França, Grécia, Japão, Luxemburgo, Noruega, Suécia e Suíça). E as resultantes recomendações sugerem a adoção de dois tipos básicos de políticas: a) políticas que estimulem a direta coordenação entre os provedores e os beneficiários das amenidades (apoio à ação coletiva e à valorização comercial); b) políticas que ajudem a mudar certas regras econômicas (regulamentações e incentivos financeiros). ${ }^{27}$

\section{Conclusões}

O próprio caráter da exposição feita nos três tópicos anteriores impede que dela se tirem verdadeiras conclusões (isto é, sínteses de confirmações ou refutações de hipóteses). Mas permite que sejam formuladas dez proposições em torno das quais deve se organizar o debate que permitirá o avanço das pesquisas sobre a face territorial do desenvolvimento:

a) É errado abordar as relações entre cidade e campo nos termos em que se desenrola o debate sociológico, isto é, de "dicotomia $\mathrm{x}$ continuum". $\mathrm{O}$ aumento da densidade demográfica nas zonas "cinzentas" - que deixaram de ser propriamente rurais e que não chegam a ser propriamente urbanas - não significa que esteja desaparecendo a contradição material e histórica entre o fenômeno urbano e o fenômeno rural. Em termos econômicos e ecológicos, aprofundam-se, em vez de diluírem-se, as diferenças entre esses dois modos de relacionamento da sociedade 
com a natureza.

b) Também é errado opor uma tendência de "ressurreição rural" à velha tese da "desertificação rural". Em termos estritamente demográficos, há áreas rurais que continuam se esvaziando e outras que se recuperam. Mas as possibilidades de dinamismo econômico dessas áreas não estão necessariamente correlacionadas às tendências demográficas, uma vez que as mais promissoras vantagens competitivas das áreas rurais são "amenidades" que dependem de heranças naturais e culturais, podendo ser até melhor aproveitadas por movimentos apenas temporários de população.

c) O processo de aproveitamento das novas vantagens competitivas tem sido muito lento porque depende dos inúmeros e pouco conhecidos determinantes do "empreendedorismo". A ênfase no caráter endógeno de tais determinantes - que está embutida no uso cada vez mais freqüente da noção de "capital social" - não deve, todavia, levar a pensar que possam ser menos interessantes os determinantes exógenos que resultam da importância que o conjunto da sociedade dá ao patrimônio natural e cultural de seus espaços rurais.

d) Fatores supranacionais - como a integração européia ou, de forma mais ampla, a regionalização internacional e a "mundialização" ou "globalização" - têm provocado uma heterogênea evolução das políticas governamentais. A crescente exposição ao comércio internacional e à aceleração do progresso tecnológico exigem mudanças estruturais que permitam remover obstáculos ao crescimento e ajudem a aproveitar novas oportunidades. Muitas dessas mudanças estruturais são de caráter subnacional, mostrando a pertinência de uma abordagem territorial, para a qual os quadros dirigentes estão, contudo, despreparados. Sabem que o principal desafio é identificar os fatores que permitiriam ampliar as oportunidades de desenvolvimento das regiões menos dinâmicas, mas também não ignoram que a resposta depende de uma explicação ainda muito precária sobre as razões desse menor dinamismo.

e) O uso cada vez mais freqüente da noção "DT: desenvolvimento territorial" (ou "espacial", como prefere a Comissão
Européia), tende a substituir a tradicional expressão "desenvolvimento regional", pois permite uma referência simultânea ao desenvolvimento local, regional, nacional, e até continental (no caso da Europa).

f) Mas essa retórica do "DT" também deve muito à evolução paralela dos debates $\mathrm{da}$ "economia industrial", da "economia rural" e da "economia regional e urbana". Nos últimos quinze anos houve nessas três disciplinas uma forte valorização da escala "local", logo seguida (ou acompanhada) da necessidade óbvia e imperiosa de não isolála das escalas superiores que vão até a "global".

g) A retórica do "DT" é certamente melhor que a do "desenvolvimento local", mas ambas estão longe de engendrar uma 'teoria \& prática' que venha, de fato, superar as divisões setoriais (primário, secundário e terciário) e também permitir um tratamento integrado da divisão espacial (cidade e campo).

h) As mudanças semânticas do debate público sempre revelam um sentimento coletivo de que noções utilizadas até determinado momento não mais dão conta da percepção que se tem dos problemas enfrentados, nem exprimem direito o que se gostaria ou pretenderia fazer em seguida. Ou seja, são mudanças que refletem as hesitações intrínsecas ao enunciado de novos projetos sociais, e, por isso mesmo, as novas noções em torno das quais se organiza o debate público costumam ser sempre muito imprecisas, fluidas e ambíguas.

i) Não há, portanto, muito interesse em saber qual pode ser a utilidade de cada um dos inúmeros adjetivos que têm sido acrescentados ao substantivo "desenvolvimento' conforme evolui o debate público sobre essa grande utopia dos últimos cinqüenta anos. Por isso, em vez de comparar o valor relativo das inúmeras maneiras pelas quais se pode subjetivamente qualificar o desenvolvimento como objetivo central das políticas públicas, o que interessa é discutir a real relevância da dimensão territorial do processo objetivo de desenvolvimento.

j) É muito cedo para saber se, além de um indiscutível progresso retórico, a noção "desenvolvimento territorial" traz algo de realmente novo para um eventual desen- 
volvimento das regiões sem dinamismo econômico, que também costumam ser chamadas de periféricas ou atrasadas. Por exemplo, se estão melhorando as chances de uma região como o sul da Itália ("Segunda Itália") romper com a estagnação, mesmo que não possa deixar de ser periférica e atrasada em comparações com as regiões mais dinâmicas. Não apenas porque a abordagem territorial só começou a engatinhar em meados dos anos 1990, mas também porque é muito difícil avaliar se as transformações positivas que estão ocorrendo no Mezzogiorno ${ }^{28}$ poderão vir a ser, de fato, favorecidas por essa nova abordagem.

Este texto, que é parte do primeiro relatório de andamento da pesquisa que o autor está realizando na Europa com auxílio da FAPESP, já incorpora alguns dos comentários gentilmente enviados pelos colegas Ademir Cazella, Eduardo Ehlers, Ignacy Sachs, e Ricardo Abramovay.

\section{Notas:}

${ }^{1}$ Conforme tipologia da OCDE baseada na proporção da população regional que vive em localidades rurais, isto é, com menos de $150 \mathrm{hab} / \mathrm{km}^{2}$. 'Essencialmente Rurais' são as regiões nas quais mais de $50 \%$ das localidades são rurais; 'Relativamente Rurais' são as regiões nas quais entre 15 e $50 \%$ das localidades são rurais; 'Essencialmente Urbanas' são as regiões nas quais menos de $15 \%$ das localidades são rurais. Ver a propósito Abramovay (1999a).

${ }^{2}$ Um excelente discussão desse problema está em Bertrand (1975).

${ }^{3}$ Ver sobre este assunto o interessante artigo de Larceneux (1996).

4 "It is impossible for a rural area to develop without automatically becoming non-rural" (Saraceno, 1994, p. 468).

${ }^{5}$ Cf. OCDE (1997).

${ }^{6}$ Parafraseando Jean Rostand, vale lembrar que é muito mais fácil se entender com quem fala outra língua do que se entender com quem dá outros sentidos às mesmas palavras...

${ }^{7}$ Realizados desde o final dos anos 1970 pelos economistas Giacomo Becattini, Gioacchino Garofoli, Sebastiano Brusco e Fabio Sforzi e pelos sociólogos Arnaldo Bagnasco, Carlo Trigilia e Vittorio Capecchi.

${ }^{8}$ Benko e Lipietz (1992); Rallet e Torre (1995); Abdelmalki e Courlet (1996); e Pecqueur (1996).

${ }^{9}$ Cf. Garofoli (1996, p. 370). Ou seja, deve ser impossível a ocorrência dessa economia "difusa" em vastas áreas do território brasileiro, embora ela seja não só possível, como muito provável, no norte gaúcho, em Santa Catarina, no sudoeste do Paraná, em algumas mesorregiões do Sudeste e do Nordeste, e até em certas microrregiões do Centro-Oeste e do Norte.

${ }^{10}$ Cf. OCDE (1998).

${ }^{11}$ Sobre a noção de "capital social", ver Abramovay (1999b).

${ }^{12}$ Cf. Maillat (1995) e Becattini e Rullani (1995).
${ }^{13}$ Cf. Becattini e Rullani (1995, p. 188-190).

${ }^{14}$ Cf. Sforzi (1996).

${ }^{15}$ cf. Friedmann e Weaver (1979); Sachs (1980); Stöhr (1981).

${ }^{16}$ Chamada de "European Spatial Development Perspective (ESDP)" ou "Schéma de Développement de l'Espace Communautaire (SDEC)".

${ }^{17} \mathrm{O}$ “Territorial Development Service" (TDS) foi criado em 1994.

${ }^{18}$ Leurquin (1998, p. 196).

${ }^{19}$ Cf. UE/ESDP (1997).

${ }^{20}$ Sendo 5 relativas às estruturas urbanas; 2 relativas à mudança do papel das áreas rurais; 7 relativas às mudanças nos transportes, comunicações e conhecimento; e 4 relativas à contínua pressão sobre as heranças natural e cultural.

${ }^{21}$ Esse programa, cuja sigla original era "ILE", passou depois a ser denominado "LEED: Local Economic and Employment Development".

22 Tradução livre de trechos do parágrafo 11 da "Nota do Secretário Geral" C(93)83, de 29/06/93.

${ }^{23}$ Estas observações resultam de uma leitura do processo verbal da reunião do Conselho, um documento "reservado" da OCDE.

${ }^{24}$ Tradução livre do tópico "Territorial Development" da brochura The OECD in the 1990s, p. 40-41.

${ }^{25}$ Cf. OCDE (1995, p. 77).

${ }^{26}$ Cf. OCDE (1993, p. 46).

${ }^{27}$ Cf. OCDE (1999:32-34).

${ }^{28}$ Fala-se mesmo de uma " grande svolta". Ver a propósito Bodo e Viesti (1997).

\section{Referências bibliográficas}

ABDELMALKI, Lashen; Claude Courlet (eds.). Les Nouvelles Logiques du Développement. Paris, L'Harmattan, 1996.

ABRAMOVAY, Ricardo. Do setor ao território: funções e medidas da ruralidade no desenvolvimento contemporâneo. Relatório de Pesquisa IPEA, (BRA/97/ 013), 1999a, $46 \mathrm{p}$.

. O capital social dos territórios: repensando o desenvolvimento rural. IV Encontro da Sociedade Brasileira de Economia Política, Porto Alegre, 01-04/06/99.

BAGNASCO, Arnaldo; TRIGILIA, Carlo (dir.). Societàe Politica nelle Aree di Piccola Impresa, Venezia, Arsenale Editrice, 1984.

BECATTINI, Giacomo. Dal 'settore industriale' al 'distretto industriale'. Alcune considerazioni sull' unità d'indagine dell' economia industriale, L'industria. Rivista di Economia e Politica Industriale, n. 1, 1979.

BECATTINI, Giacomo; RULLANI, Enzo. Système local et marché global. Le district industriel. In: Alain Rallet; André Torre (coord.). Économie Industrielle et Économie Spatiale, Paris, Economica, p. 171-190, 1995.

BENKO, Georges; LIPIETZ, Alain (dir.). Les Régions qui Gagnent; Districts et réseaux: les nouveaux paradigmes de la géographie économique, Paris, PUF, 1992.

BERTRAND, Georges. Pour une histoire écologique de la France rurale. In: Georges Duby; Armand Wallon (dir.). Histoire de la France Rurale, Paris, Éditions du Seuil, vol I (Ouverture), p. 39-118, 1975. 
BODO, Giorgio; VIESTI, Gianfranco. La Grande Svolta; Il Mezzogiorno nell'Italia degli anni novanta. Roma, Donzelli, 1997.

BRUSCO, Sebastiano. The idea of the industrial district: its genesis. In: Frank Pike, Giacomo Becattini; Werner Sengenberger (eds.). Industrial Districts and Inter-firm Cooperation in Italy. Genebra, International Labour Organisation (International Institute for Labour Studies), 1990, p. 10-19.

Trust, social capital and local development: some lessons from the experience of the Italian districts. In: OCDE. Networks of Enterprises and Local Development. Paris, OCDE, 1996, p. 115-9.

FRIEDMANN, J.; WEAVER, C. Territory and function: the evolution of regional planning, Londres, Edward Arnold, 1979.

GAROFOLI, Gioacchino. Industrialisation diffuse et systèmes productifs locaux: un modèle difficilement transférable aux pays en voie de développement. In: Lashen Abdelmalki; Claude Courlet (eds) Les Nouvelles Logiques du Développement. Paris, L'Harmattan, 1996, p. 367-81.

LARCENEUX, André. Les nouveaux chantiers de la théorie économique spatiale. In: Bernard Pecqueur (ed.) Dynamiques Territoriales et Mutations Économiques, p. 137156, Paris, L'Harmattan, 1996.

LEURQUIN, Bernard. Le pays: un espace pertinent pour l'aménagement et le développment du territoire. In: Guy Loinger; Jean-Claude Némery (eds.). Recomposition et Développment des Territoires; Enjeux économiques, processus, acteurs. Paris, L'Harmattan, 1998, p. 191-210.

MAGNAGHI, Alberto. Il patrimonio territoriale: un codice genetico per lo sviluppo locale autosostenibile. In: Alberto Magnaghi (dir.). Il Territorio degli Abitanti; Società locali e autosostenibilità. Milão, Dunod, 1998, p. 3-20.

MAILLAT, Denis. Milieux innovateurs et dynamique territoriale. In: Alain Rallet; André Torre (coord.). Économie Industrielle et Économie Spatiale. Paris, Economica, 1995, p. 211-232.

OCDE. What Future for Our Countryside? A Rural Development Policy, Paris, OCDE, 1993.

(brochura)
Local Responses to Industrial Restructuring in Austria, (Territorial Development Service). Paris, OCDE, 1995.

. Le Partenariat aux États-Unis (Examen de l'OCDE des Politiques Rurales; Territorial Development Service), Paris, OCDE, 1997.

Fostering Entrepreneurship; The OECD Job Strategy. Paris, OCDE, 1998.

Cultivating Rural Amenities; An Economic Development Perspective, (Territorial Development Service), Paris, OCDE, 1999.

PECQUEUR, Bernard (ed.). Dynamiques Territoriales et Mutations Économiques, Paris: L'Harmattan, 1996.

RALLET, Alain; TORRE, André (coord.). Économie Industrielle et Économie Spatiale, Paris, Economica, 1995.

SACHS, Ignacy. Stratégies de l'Éco-développement, Paris, Les Éditions Ouvrières, 1980.

SARACENO, Elena. Alternative readings of spatial differentiation: The rural versus the local approach. In: Italy European Review of Agricultural Economics, 21, 1994, 451-474.

SFORZI, Fabio. The quantitative importance of Marshallian industrial districts in the Italian economy. In: Frank Pike, Giacomo Becattini; Werner Sengenberger (dir.). Industrial Districts and Inter-firm Co-operation in Italy, p. 75-107, Genebra: International Labour Organisation (International Institute for Labour Studies), 1990.

Local systems of small and medium-sized firms and industrial changes. In: OCDE. Networks of Enterprises and Local Development. Paris, OCDE, 1996, p. 99-113.

STÖHR, W. B. Development from below: the bottomup and periphery-inward development paradigm. In: W. B. Stöhr; D. R. F Taylor (eds.). Development from Above and Below? The Dialectics of Regional Planning in Developing Countries, Chichester, Wiley, 1981.

UE/ESDP. European spatial development perspective. First official draf, Presented at the informal meeting of Ministers responsible for spatial planning of the member states of the European Union", Noordwijk, 09-10/06/97, 72 p. 